The Social Sciences 6 (5): 328-331, 2011

ISSN: $1818-5800$

(C) Medwell Journals, 2011

\title{
The Study of Professional Competence Requirement for Thailand's Off-Set Printing Industry for Expands to Training Course
}

\author{
Phongyut Juntong, Sittichai Kaewkuekool and Suchapa Netpadit \\ Faculty of Industrial Education and Technology, \\ King Mongkut's University of Technology, Thonburi, Bangkok
}

\begin{abstract}
The purpose of research was aimed at explore the professional competence for Thailand's offset printing industry. Discussion group of experts and survey questionnaire methodology was used in this research. The surveyed participants in this research were the managers and supervisors of the press operators in commercial printing companies. To analyze the result of surveys, several statistical methods including mean, $\mathrm{SE}$ and rank were conducted. The results from a discussion group of experts were that printing operators could be classified into 4 levels as follow; printing operator's assistant, second hand printing operator, first hand printing operator and printing operator head. Afterwards, the professional competency of the printing operator's assistant which had 7 main topics as follow; knowledge about color printing operation, materials and equipment, using technician's tools, practice in offset printing, English for printing operators, maintenance and safety during work.
\end{abstract}

Key words: Professional competence, offset printing, printing industry, press operators, surveys, Bangkok

\section{INTRODUCTION}

Background and motive of the problem: $\operatorname{In} 1835$, American Board of Commissioners for Foreign Mission bought Thai type from Singapore to Thailand. M.D. Dan Beach Bradley and his group brought it to Thailand. This Thai type and old plate was made of wood and stone which came from Bengal in India. On June 3, 1836 the 1st book in Thai was printed at the 1st time (Sathirakul, 1985). Since, the 1st day of printing in Thailand until 2009, it is 173 years. Thailand has developed in terms of printing industry for a long time both in working process and modern technology which is brought from foreign countries to increase the productivity. Thailand is a free country which develops its potentials in competition all the time because this is an important factor to get advantages in trading.

The policy of the government therefore, focuses on the development of production potential to increase overall value of the product in the country along with the development of exportation which will lead to the glory of the nation in the long run. The printing and packaging industry is one of the most important industries which aim for exportation in the form of type and package. Free trade helps extend the distribution of Thai products. In 2004, Thailand could export for around 10,000 million Baht and in 2007, Thailand aimed to export for 30,000 million Baht. Besides the strategies used for exportation, there need to be strategies for the development of the internal structure of printing and packaging industry to meet the expanding area of the exportation which must be done at the same time. To illustrate a center for the research and development of standards in printing and packaging industry must be established to meet the world's standards, training course and to build new entrepreneurs in the industry. More advantages are about the development of the personnel in educational institutes in the form of co-education, the research and the development in the printing materials as well as the development of competency standards of the national labor in the field of sheet-fed printing operator and other fields related to printing and packaging industry (Phayakaso, 2004).

According to the survey done in 2004 , there are 2,463 printing houses which have registered with the Department of Industrial Works, Ministry of Industry or around $90 \%$ of all printing houses. The majority or $74 \%$ are in Bangkok and sub-urban areas. The rest are in large cities all around the country. The personnel in the printing and packaging industry are around 120,000 but only $10 \%$ graduated with the degrees in printing and packaging. This would result in problems about lack of knowledge and skills to receive new technology which requires ability in language and computer during work. Therefore, printing and packaging industry still suffers from lack of

Corresponding Author: Phongyut Juntong, Faculty of Industrial Education and Technology,

King Mongkut's University of Technology, Thonburi, Bangkok 
skillful printing operators with direct experience in printing (Pajonklaew, 2002). According to Tengbucha (2001), it was found that most large-scaled and middle-scaled printing houses provided their staff with training outside. However, the problems were that the speakers from outside lacked the knowledge and skills which the entrepreneurs demanded that the trainers lacked skills in teaching and allowing their staff to study in higher education required a long time and the skills did not comply with the works.

Besides this lack of the skilled persons in printing industry, it was also found that the personnel in the printing industry at present do not meet the requirements of the enterprises. According to the research on the problems, the major problems of sheet-fed printing operators in the enterprises were about lack of knowledge, skills and good attitude towards their work. The problems which the enterprise owners would like to solve the most were lack of knowledge in using printing machine, knowledge and skills in offset printer maintenance as well as other devices. The printing house owners also require responsible workers who like to gain more knowledge and skills in their work and to use the materials efficiently (Juntong et al., 2007a).

According to the problems found in the printing house, the researchers asked the same questions with the sheet-fed printing operators and found that $97.5 \%$ of basic level sheet-fed offset printing operators considered the training as important for their work. The reason was that they would like to know technology, more techniques and new working methods. Sheet-fed printing operators need to be trained both in theory and in practice at high level (Juntong et al., 2007b). According to the importance of such problem, it could be seen that there should be competency standards for 4-color sheet-fed offset printing operator as required by the enterprises. This must be done in cooperation with the experts in educational field so that the competency will be used to develop courses or curriculum for the printing operators in the industry. This is also a way for other researchers to develop the personnel according to the real demand of the industry in the future.

\section{Literature review}

Competence: Competence is the ability of professionals who have the knowledge, expertise and attitude needed to execute the job. Lee (1999) and Huang (1996) stated that competence is the capability of doing their future jobs or activities. This clearly indicates that a competent professional should have necessary knowledge, skills and attitude to do certain activities and jobs. Competency standards describe the knowledge, skills and attitudes that need to be applied to minimize risks. They include units (to define the broad area of performance), elements (specific skills) and performance criteria (demonstrated outcomes for each variable). They can include a range of variables to allow for application in different contexts and are underpinned by evidence to support the required knowledge, skills and attitudes (Meyer and Work Cover NSW, 1998).

A competency is an underlying characteristic of an individual that is causally related to criterion-referenced effective and/or superior performance in a job or situation (Spencer and Spencer, 1993).

Professional competences: Professional competence should include three factors:

Knowledge: Facts and information needed to be known by professionals in their jobs to promote and achieve certain functions effectively. These include an emphasis on the ability of knowledge, principles of the performance of the expertise, academic principals (do you mean principles?) of the theories, human relationships and evaluation levels of the knowledge.

Skills: The ability of using the knowledge to solve the specific problems. The evaluation can be observed from the achievement of the practical performance as well as the professional performance of the processes and social skills.

Attitude: Professional recognition, professional emotion and professional performance. Even though, attitude is hard to evaluate, it should not be neglected (Chisholm and Ely, 1976; Javis, 1983).

\section{MATERIALS AND METHODS}

This research is focused on the key requirements of the professional competence for the offset participants. In this study, the quantitative research method was used to analys is to questionnaire results. To formulate the survey questionnaire, reviewing and analyzing the literature were used as the theoretical bases. The related information was collected and examined to what the professional competence that the offset printing participants should have.

The initial survey questionnaire was developed in professional competence items within categories. The final survey questionnaire was modified, generated and delivered based on the feedback from the experts and 
scholars. This research used the questionnaire about the opinions of participants in this research were the managers and supervisors of the press operators in commercial printing companies about key professional competence for the printing operator's assistant participant. And focus group was an expert was held about key professional competence for the printing operator's assistant participant.

Sample: The 9th experts in the focus group about combination and the key professional competence for the printing operator's assistant participant form enterprises and technical school. The sampling group for the study on the opinions about combination and the key professional competence for the printing operator's assistant participant of industrial printing and packaging enterprises composed of enterprise owners, printing house managers and ssupervisors form 138 enterprises in Bangkok and sub-urban areas.

\section{RESULTS AND DISCUSSION}

General status of sampling group: The general status of respondents, it was found that the sampling group age was on the average from 31-50 years of old with bachelor's degree and 11 years of working experience. Most of them worked as department heads in printing houses where, there were $>50$ employees.

Develop professional competence: Focus group discussion on the classification of offset printing operator skills. From the focus group discussion, the panel which consists of offset printing operators, classified 4 levels as follow:

- Basic level printing operator (printing operator's assistant) means a person who is interested in working as a multi-colored offset printing operator but who has no knowledge, skills and working experience

- Middle level printing operator (second hand printing operator) means a person who has knowledge, abilities, experience and basic skills for working with a multi-colored printer. He or she has had some experience as a basic level printing operator before

- High level printing operator (first hand printing operator) means a person who has knowledge, abilities, experience and good skills for working with a multi-colored printer. He or she has had experience as a middle level printing operator before

- Expert printing operator (printing operator head) means a person who has knowledge, abilities, experience and good skills for working with a multi- colored printer. He or she can solve and analyze printing problems. He or she has had experience as a high level printing operator before

Descriptive information of the professional competence: According to the statistical results from the survey if the mean of the competence item is $>3.00$ it means that competence item is the basic professional competence that the offset printing participant should have. If the competence item is $>4.00$ it means that competence item is extremely important professional competence. In the key, professional competence as follow; English for offset printer maintenance, English for parts of offset printer, English for occupational safety, meaning and principles,

Table 1: Key professional competence for the survey questionnaire participant

\begin{tabular}{|c|c|c|}
\hline Key professional competence & Mean \pm SE & Ranl \\
\hline Meaning and principles & $3.77 \pm 1.07$ & 43 \\
\hline Offset printing process & $3.81 \pm 1.06$ & 41 \\
\hline Visibility and color combination & $3.90 \pm 1.00$ & 39 \\
\hline Types of 4-color offset printer & $4.27 \pm 0.72$ & 18 \\
\hline Parts of 4-color offset printer & $4.38 \pm 0.70$ & 8 \\
\hline Pre-press process & $4.15 \pm 0.67$ & 30 \\
\hline Press/production process & $4.37 \pm 0.68$ & 10 \\
\hline Post-press process & $4.35 \pm 0.66$ & 11 \\
\hline Printability study & $4.28 \pm 0.70$ & 17 \\
\hline Preparing ink & $4.34 \pm 0.73$ & 15 \\
\hline Preparing plates & $4.28 \pm 0.70$ & 18 \\
\hline Preparing blankets & $4.40 \pm 0.68$ & 7 \\
\hline Preparing fountain & $4.35 \pm 0.72$ & 12 \\
\hline Preparing gum arabic & $4.27 \pm 0.86$ & 19 \\
\hline Preparing other chemicals & $4.22 \pm 0.83$ & 24 \\
\hline General tools for technicians & $4.22 \pm 0.68$ & 25 \\
\hline Measuring tools & $4.25 \pm 0.71$ & 20 \\
\hline Tools for printing operators & $4.25 \pm 0.60$ & 22 \\
\hline Tools for printer maintenance & $4.32 \pm 0.65$ & 16 \\
\hline Densitometer & $4.38 \pm 0.68$ & 9 \\
\hline Reading orders & $4.44 \pm 0.60$ & 2 \\
\hline Checking and preparing materials & $4.50 \pm 0.60$ & 1 \\
\hline Preparing studys, wasted studies & $4.41 \pm 0.67$ & 5 \\
\hline Adjusting study feeder & $4.42 \pm 0.67$ & 3 \\
\hline Checking plates & $4.35 \pm 0.66$ & 13 \\
\hline Cleaning plates, blankets and impression & $4.42 \pm 0.69$ & 4 \\
\hline Preparation and job changes & $4.41 \pm 0.64$ & 6 \\
\hline Cleaning printing units & $4.35 \pm 0.79$ & 14 \\
\hline Cleaning water unit and fountain container & $4.20 \pm 0.75$ & 26 \\
\hline Cleaning printer and tools & $4.24 \pm 0.78$ & 23 \\
\hline Cleaning plates and keeping plates in good condition & $4.17 \pm 0.74$ & 29 \\
\hline English for technician's tools & $3.88 \pm 0.92$ & 40 \\
\hline English for occupational safety & $3.75 \pm 0.84$ & 44 \\
\hline English for parts of offset printer & $3.68 \pm 0.90$ & 45 \\
\hline English for offset printer maintenance & $3.68 \pm 0.90$ & 46 \\
\hline English for caution sign for operation around printer & $3.80 \pm 0.95$ & 42 \\
\hline Cleaning printer & $4.11 \pm 0.60$ & 32 \\
\hline $5 \mathrm{~S}$ activities & $4.15 \pm 0.69$ & 31 \\
\hline Lubricating the printer & $4.18 \pm 0.64$ & 27 \\
\hline Maintaining the printer by one self & $4.18 \pm 0.66$ & 28 \\
\hline Causes of work accidents & $4.10 \pm 0.74$ & 34 \\
\hline Dangers from chemicals during & $4.05 \pm 0.75$ & 36 \\
\hline Tools for preventing accidents during work & $4.10 \pm 0.74$ & 35 \\
\hline Fire and how to prevent it & $4.11 \pm 0.75$ & 33 \\
\hline Safety rules in the factory & $4.05 \pm 0.67$ & 37 \\
\hline Labor laws & $3.95 \pm 0.71$ & 38 \\
\hline
\end{tabular}


offset printing process, English for technician's tools, visibility and color combination and labor laws. This is unimportant item within the key professional competence category (Table 1 ).

\section{CONCLUSION}

The purpose of this research was to analysis the explore the professional competence for Thailand's offset printing industry. The conclusion can be made as followed; From the observations of the focus group of experts, printing operators can be classified into 4 levels including basic level (printing operator's assistant), middle level (second hand printing operator), high level (first hand printing operator) and expert (printing operator head) printing operators.

The key professional competence item of checking and preparing materials, reading orders and adjusting study feeder were the most important item in the key professional competence category.

In the category, the key professional competence as follow; English for offset printer maintenance, English for parts of offset printer, English for occupational safety, meaning and principles, offset printing process, English for technician's tools, visibility and color combination and labor laws. This is unimportant item within the key professional competence category. Form the result can apply knowledge to training curriculum development to meet Thailand's offset printing industry.

\section{ACKNOWLEDGEMENTS}

Application to educational institutions could be a new method to improve the curriculum and teaching of skills as well as adding data about attitudes towards work. Moreover, industrial sectors, such as printing houses, could use this to train their workers and develop their competency skills and reading ability to achieve high performance efficiency in each level in a relatively short period of time by using a standard vocational competency course as a guide to develop the knowledge and skills of offset printing operators. An improvement of course training packages in the enterprises as well as the development of printing competency skills would be applied by human resource development in order to set the criteria for career path advancement. This would be directly relevant to the real problems that occur in the Thai printing industry.

\section{REFERENCES}

Chisholm, M.E. and D.P. Ely, 1976. Reflections from a crystal ball. Audiovisual Instruction 21, 1. ERIC Document Reproduction Service No. EJ131254.

Huang, C., 1996. Increasing the quality of vocational. Education technological and vocational education. Bimonthly, 49: 6-13.

Javis, P., 1983. Professional Education. Caron Publications, London.

Juntong, P., S. Kaewkuekool and S. Netpadit, 2007a. The study of problem and requirements about training of printing operator and chief in the certified offset printing factory. Proceedings of the ICASE Asian Symposium: Science Education for all: Toward Sustainable Development Regardless of Resource, Nov. 6-9, Thailand, pp: 95-95.

Juntong, P., S. Kaewkuekool and S. Netpadit, 2007b. The Study of problem and requirements of state offset technician standard for sheet-fed offset printing operator. Proceedings of the 8th Asia Pacific Industrial Engineering and Management System and Chinese Institute of Industrial Engineers Conference, Dec. 9-12, National Yunlin University of Science and Technology, Taiwan, pp: 205-205.

Lee, L., 1999. The cross of technology and vocational education. National Taiwan Normal University, Taipei, Taiwan,

Meyer, L. and Work Cover NSW, 1998. Manual Handling Competencies for Nurses. NSW Nurses' Association, Camperdown, New South Wales, pp: 54.

Pajonklaew, P., 2002. The status of Thailand printing houses in 2001. Thailand Printing Day, Thailand, pp: $74-80$.

Phayakaso, W., 2004. The direction and potential development of Thailand printing industry. Thai Printing Federation, Thailand, pp: 14-17.

Sathirakul, G., 1985. History of Book and Publishing. Bangkok Rungsilp Publishing, Thailand, pp: 11.

Spencer, L.M. and S.M. Spencer, 1993. Competence at Work: Models for Superior Performance. John Wiley and Sons, New York, ISBN-13: 9780471548096, pp: 372.

Tengbucha, A., 2001. Training technique for foreman. Faculty of Industrial Education, KMITNB, Thailand, pp: $5-12$. 